\title{
Hemp Shive-Based Bio-Composites Bounded by Potato Starch Binder: The Roles of Aggregate Particle Size and Aspect Ratio
}

\author{
Ina Pundiene', Laura Vitola1*, Jolanta Pranckeviciene², Diana Bajare ${ }^{1}$ \\ 1 Institute of Materials and Structures, Riga Technical University, Kalku 1, LV-1658, Riga, Latvia \\ 2 Institute of Building Materials, Vilnius Gediminas Technical University, Sauletekio Av. 11, LT-10223, Vilnius, \\ Lithuania \\ *Corresponding author's e-mail: laura.vitola_1@rtu.lv
}

\begin{abstract}
According to European regulations, the construction industry supports and strives to save non-renewable natural resources, increases the share of reusable resources in production and attempts to use renewable natural resources as much as possible by creating alternative building materials, such as bio-composites. Various building materials containing hemp shives (HS) are relatively popular and are often used in practice. The properties of these materials vary widely due to the usage of significantly different binders and because the parameters of the HS can significantly affect the properties of the bio-composite. Potato starch (PS), the properties of which have not been studied extensively in the past, was used as a binder in this study. Depending on the type of manufacturing process and technology employed for hemp fibre production, the HS particle shape and size can vary widely, which leads to the following statement: the properties of bio-composites produced by using the same method, but with different HS, may differ significantly. In order to investigate the effects of HS on the properties of bio-composites, including the hydro-thermal properties, an in-depth study was conducted to examine the structure, the physical properties and the particle size of HS. It was discovered that in order to obtain a material of higher compressive strength, the HS with smaller dimensions should be used; however, if enhanced thermal properties are required, the HS with longer particles should be used.
\end{abstract}

Keywords: potato starch binder; hemp shives; bio-composite; compressive strength, thermal conductivity.

\section{INTRODUCTION}

Hemp shive (HS) based composite materials comply with the requirements of the High Quality Environmental (HQE) standard and have a low overall environmental impact due to carbon dioxide storage (Bourdot et al. 2017). When storing carbon, HS can capture up to two tonnes of $\mathrm{CO}_{2}$ per tonne of fibre, which makes utilising shives in composites a particularly attractive option (Jiang et al. 2019).

Hemp fibres and shives are widely used as bio-insulation materials for buildings (Pickering et al. 2016). The main advantages of hemp fibresand shives-based materials are as follows: they are renewable, minimise environmental impact and have low densities and thermal conductivities. However, there are some disadvantages as well: these materials have a high moisture absorption capacity, which results in swelling, lower strength and greater variability of properties (Dicker et al. 2014). Nevertheless, some recent studies (Cigasova et al. 2013; Seng et al. 2019) have revealed that different binders (e.g. lime, Portland cement or a mixture of lime and Portland cement) when used to produce bio-composites demonstrate the densities ranging from $808 \mathrm{~kg} / \mathrm{m}^{3}$ to $1156 \mathrm{~kg} / \mathrm{m}^{3}$ and compressive strengths from $0.70 \mathrm{MPa}$ to 2.2 $\mathrm{MPa}$. Compared to the bio-composites produced using lime and cement-based binders, the bio-composites made from starch, due to their low density and high porosity (approximately 
$89 \%$ ), have better thermal insulation properties - their thermal conductivity varies from 0.0634 $\mathrm{W} /(\mathrm{m} \cdot \mathrm{K})$ to $0.0738 \mathrm{~W} /(\mathrm{m} \cdot \mathrm{K})$. These thermal properties are explained by the molecular structure of components and the extremely high porosity of HS. The porosity of HS comprises macropores (sizes of $1 \mathrm{~mm}$ induced by the imperfect arrangement of particles) (Collet et al. 2008), mesopores and micropores (mainly found in a plant aggregate structure) (Collet et al. 2013).

The literature review (Le et al. 2015; Benitha Sandrine et al. 2015; Arunas Kremensas et al. 2017; Kairyte et al. 2018) reveals that starch is an excellent alternative to traditional, non-organic binding materials. However, starch (or starchbased) products need to be improved to meet more stringent requirements of mechanical properties and resistance to bio-corrosion.

A few studies have been carried out on HS with corn starch (Balčiunas et al. 2013a), PS (Bénézet et al. 2012), wheat starch (Le et al. 2014a; 2015) and hybrid organic and inorganic binders (Sassoni et al. 2014). Starch is a natural polymer directly extracted from renewable resources (plants), characterised by low cost, the ability to be fully compostable without leaving behind any toxic residues and its wide availability for biocomposite applications (Balčiunas et al. 2013b). The characteristics of PS have not been widely studies. However, it is a commonly used alternative for corn starch in Nordic countries. The two major biomacromolecules of starch, regardless of its origin, are amylose and amylopectin. Native starch granules are well known to possess multilevel structures, from macro to molecular scales, i.e. starch granules $(<1-100 \mu \mathrm{m})$; alternating amorphous and semi crystalline shells (growth rings) (100-400 nm); crystalline and amorphous lamellae (periodicity) $(9-10 \mathrm{~nm})$; and macromolecular chains ( 1 nm) (Xie, Halley, and Avérous 2012). Different starches have varying initial swelling stage temperatures: corn starch (from $62^{\circ} \mathrm{C}$ to between $67^{\circ} \mathrm{C}$ and $72^{\circ} \mathrm{C}$ ), PS (from $58^{\circ} \mathrm{C}$ to between $63^{\circ} \mathrm{C}$ and $68^{\circ} \mathrm{C}$ ), wheat starch (from $58^{\circ} \mathrm{C}$ to between $61^{\circ} \mathrm{C}$ and $64^{\circ} \mathrm{C}$ ) and rice starch (from $68^{\circ} \mathrm{C}$ to between $74^{\circ} \mathrm{C}$ and $78^{\circ} \mathrm{C}$ ) (Liu et al. 2017). Starch cannot be thermally processed without water. Water plays a role by lowering the melting temperature and plasticising the starch polymer. Consequently, in practical processing applications, water acts as a plasticiser (Xie, Halley, and Avérous 2012).
Following gelatinisation, in terms of mechanical strength, starch is uninfluenced by temperature or variation in relative humidity (Follain et al. 2005; Delville et al. 2003). Compared to most traditional synthetic polymers, thermoplastic starch-based materials suffer from several drawbacks (e.g. poor mechanical properties and water sensitivity). Several studies have been conducted on this subject [Gironès et al. 2012, Kairyte et al. 2018]. Nevertheless, thermoplastic starchbased materials are completely eco-friendly and meet the basic requirements of fibreboards standard EN 622-4 (BS EN 622-4:2019 Fibreboards. Specifications Requirements for Softboards - European Standards).

Researchers have been trying to improve the properties of bio-composites in various ways, through the additional treatment of hemp fibre surfaces with various substances: sodium hydroxide $(\mathrm{NaOH})$, ethylenediaminetetraacetic acid (EDTA), calcium hydroxide $\left(\mathrm{Ca}(\mathrm{OH})_{2}\right)$, polyethyleneimine (PEI) and calcium chloride $\left(\mathrm{Ca}\left(\mathrm{Cl}_{2}\right)\right)$ (Sandrine et al. 2015; Gironès et al. 2012; Kremensas et al. 2019). The chosen treatment method increases the effectiveness of the contact zones between the bio-composite particles and the binder, but, in most cases, such pre-treatment is non-ecological, because the issues related to water recycling having the negative environmental impact caused by the harmful additives used for treatment, remain unresolved. Some studies have been conducted by changing the proportion of different HS particle sizes in bio-composites for the purpose of improving the mechanical and water uptake properties of the material. For example, wheat starch-based bio-composites with different proportions of HS, $0 / 5 \mathrm{~mm}$ and $0 / 20 \mathrm{~mm}$ fractions (15 wt. $\%$ and 85 wt.\%, 30 wt.\% and 70 wt.\%) having a starch/ water ratio of 0.18 , were studied (Bourdot et al. 2017). The HS/starch ratio increased in the composition from 8 to 10 . The results indicated that when the proportion of $0-5 \mathrm{~mm}$ HS was increased in the composition from $15 \%$ to $30 \%$, it led to a significant enhancement of the mechanical properties (by 10\%) and hygric properties (by 4-5\%) of the bio-composite. Increasing the shives/starch ratio in HS from 8 to 10 reduced the compressive strength of the bio-composite.

The majority of the studies carried out on composites have a shives/starch ratio that varies from 6 to 14, while the starch/water ratio varies from 0.18 to 0.25 (Bergeret and Benezet 2011; 
Gironès et al. 2012; Ashok et al. 2018). It can be observed that the density of bio-composites decreases when the HS/starch ratio increases. The dry density of the resulting composites varies in the range of $150-450 \mathrm{~kg} / \mathrm{m}^{3}$. The compressive strength mostly varies in the range of $0.3-$ 1.1 MPa, and for composites with higher densities, this range varies from 1.5 MPa to 3.6 $\mathrm{MPa}$.

As observed from (Bénézet et al. 2012), when the starch/water ratio increased till it reached a value of 5.88, at a sufficiently low density of $242 \mathrm{~kg} / \mathrm{m}^{3}$, the bio-composite having a HS/PS ratio of 10 exhibited significantly improved mechanical properties: flexural strengths of 4.14, 3.76 and $3.53 \mathrm{MPa}$ at $33 \%, 56 \%$ and $75 \%$ relative humidity, respectively; and water absorption of $33 \%, 56 \%$ and $75 \%$ at $6.1,8.1$ and $11.1 \%$ relative humidity, respectively.

The HS fraction $(2.5 / 5 \mathrm{~mm})$, corn starch (with a starch/water ratio of 1.2) and HS/starch ratio varying from 0.33 to 0.45 were used in the study conducted by (Balčiunas et al. 2013b). When the HS/starch ratio increased from 0.3 to 0.5 , the compressive strength of the composites increased from $1424 \mathrm{kPa}$ to $1913 \mathrm{kPa}$. The density of the resulting bio-composites ranged from $260 \mathrm{~kg} / \mathrm{m}^{3}$ to $444 \mathrm{~kg} / \mathrm{m}^{3}$. The maximum compressive strength was discovered in the specimens that were formed from shives of $2.5 / 5 \mathrm{~mm}$ fractions and HS/starch ratios of 0.4 . Thermal conductivity of the obtained samples ranged from $0.074 \mathrm{~W} /(\mathrm{m} \cdot \mathrm{K})$ to $0.112 \mathrm{~W} /(\mathrm{m} \cdot \mathrm{K})$.

Another study (Kremensas et al. 2019) revealed the results of novel bio-composite boards by considering the aggregate of the different HS fractions $(2.5 / 5 \mathrm{~mm}, 5 / 10 \mathrm{~mm}$ and $5 / 20 \mathrm{~mm}$ using corn starch as a binder. When the shives/ starch ratio was decreased from 10 to 2 , the density of the bio-composites increased from $280 \mathrm{~kg} /$ $\mathrm{m}^{3}$ to $410 \mathrm{~kg} / \mathrm{m}^{3}$. The lowest thermal conductivity $(0.0605-0.0630)$ was obtained for the samples with a HS fraction of $2.5 / 5 \mathrm{~mm}$.

Although the outcome could possibly be significant, the impact of different HS particle fractions on the properties of bio-composites has not been extensively studied. Boudot et al. have studied the bio-composites composed of different sized particles: $0-5 \mathrm{~mm}$ and $0-20 \mathrm{~mm}$ HS in the proportions 15/85 and 30/70, respectively (Bourdot et al. 2017). The pore volume and pore size of the samples decreased when the proportion of the HS fraction $0-20 \mathrm{~mm}$ in the composite was $85 \%$. However, the compressive strength observed was
$12 \%$ lower than in the bio-composite with the hemp shives fraction $0-5 \mathrm{~mm}$ (having a proportion of $30 \%$ ). This meant that longer particles can decrease the mechanical properties of a composite. The same observation was made in (Le et al. 2015), where it was revealed that longer composites possessed 30\% lower mechanical properties. The moisture adsorption property of a bio-composite will vary based on the length and particle size: the bio-composites with longer particles reveal lower moisture adsorption characteristics. This indicates that the bio-composites having enhanced properties can be obtained without any additional surface treatment (with sodium hydroxide $(\mathrm{NaOH})$, ethylenediaminetetraacetic acid (EDTA), calcium hydroxide $\left(\mathrm{Ca}(\mathrm{OH})_{2}\right)$, polyethyleneimine $(\mathrm{PEI})$ or calcium chloride $\left.\left(\mathrm{CaCl}_{2}\right)\right)$, but just by choosing the most appropriate mechanical pre-treatment method of HS, e.g. crushing.

A literature review reveals that using a HS/ starch ratio of below 6 for producing bio-composites has not been explored in detail, and the corresponding aspect ratio of the examined HS has not been evaluated (Arunas Kremensas et al. 2019; 2017). In this study, a hemp/PS ratio of 2:5 was used, and its impact on the physical and mechanical properties of a bio-composite material was studied. Two types of commercially available HS, differing in size, shape and surface nature were used. The difference in the HS used was in their granulometric composition and aspect ratio. Hemp shives marketed as type B used in this study had a certain amount of long fibres that could affect the properties of the bio-composite, because the nature of these fibres differs from the shorter ones. Particle size of the HS depends on the hemp processing technology. It is crucial to choose the right material for producing bio-composites with desirable properties. PS, as a natural binder, in various proportions was examined for this study. The experiments were carried out to determine the optimal HS/starch ratio that could produce the desired strength and thermal insulating properties of the bio-composite.

The aim of this study was to characterise the effects of the HS particle granulometry and aspect ratio (expressed as the ratio between the length and the width of the particles) on the properties of the resulting bio-composite made of HS and PS binder. Through this study, an improved understanding of bio-composites with varying HS 
particle aspect ratio, including their mechanical and water absorption properties, was acquired.

\section{MATERIALS AND METHODS}

\section{Materials}

\section{Starch-based binder}

The starch binder used in this study was prepared from PS (Natilor) supplied by a company called Aloja Starkelsen in Latvia. The bulk density of the starch was $595 \mathrm{~kg} / \mathrm{m}^{3}$, the amylose content was $26.9 \%$, moisture content was $15.1 \%$ and the gelatinisation temperature was $64^{\circ} \mathrm{C}$. This temperature, $64^{\circ} \mathrm{C}$, was used for swelling and gelatinising starch granules in water media.

\section{Hemp shives}

The HS is the most commonly used plant origin aggregate. Researchers generally compare two types of HS: HS-A (Figure 1A) - commercially available HS, grown and processed in Lithuania and obtained from JSC Natural Fibre; and HS-B (Figure 1B) - commercially available HS, grown and processed in Latvia and obtained from the JSC Latgale Agricultural Science Centre. The bulk density, specific heat capacity, thermal conductivity, maximum dimensions of the particle (length, thickness and width), moisture

Table 1. Hemp shive properties

\begin{tabular}{|c|c|c|c|}
\hline \multicolumn{2}{|c|}{ Property } & HS-A & HS-B \\
\hline \multicolumn{2}{|l|}{ Max length $(\mathrm{mm})$} & 40.0 & 25.0 \\
\hline \multicolumn{2}{|l|}{ Max width (mm) } & 3.8 & 4.9 \\
\hline \multirow{3}{*}{ Aspect ratio } & Min & 2.9 & 1.0 \\
\hline & Max & 16.3 & 7.8 \\
\hline & Average & 7.0 & 2.9 \\
\hline \multicolumn{2}{|c|}{ Max thickness (mm) } & 1.4 & 1.7 \\
\hline \multicolumn{2}{|l|}{ Bulk density $\left(\mathrm{kg} / \mathrm{m}^{3}\right)$} & 80 & 81 \\
\hline \multicolumn{2}{|c|}{ Specific heat capacity $\mathrm{Cp}(\mathrm{J} /(\mathrm{kgK}))$} & 1270 & 1240 \\
\hline \multicolumn{2}{|c|}{ Thermal conductivity $(\mathrm{W} /(\mathrm{m} \mathrm{K}))$} & 0.043 & 0.045 \\
\hline \multicolumn{2}{|l|}{ Moisture (\%) } & 4.9 & 5.1 \\
\hline \multicolumn{2}{|c|}{ Water absorption after 24 hours (\%) } & 456 & 584 \\
\hline
\end{tabular}

content and the kinetic water absorption capacity are indicated in Table 1 . The granulometry composition data of HS is presented in Table 2. HS-A has longer shives in its composition (with the longest dimension up to $40 \mathrm{~mm}$ ). HS-B mainly comprises the particles with $25 \mathrm{~mm}$ as the longest dimension in its composition. It can be observed that in HS-B, the $1-15 \mathrm{~mm}$ fraction particles are dominant (88.8\%). In HS-A, 50.8\% of the composition comprises the $1-15 \mathrm{~mm}$ fraction particles, and the longest particles constitute $33.4 \%$ of the total composition. The macrostructures of bulk HS-A and HS-B hemp shives are indicated in Figure 1A and Figure 1B, while the kinetic water absorption behaviour is presented in Figure 1C.

\section{Sample composition and preparation process}

The hemp-starch bio-composite material comprises potatoes starch binder and HS. Four compositions were prepared with HS-A and four compositions with HS-B. In all of the compositions, starch binder $+\mathrm{HS} /$ water ratio was constant, but the HS/starch ratio was different (Table 3).

For preparing the target composition, gelatinised PS was first prepared as follows: a certain amount of PS was weighted (100 g, $150 \mathrm{~g}, 200 \mathrm{~g}$ and $250 \mathrm{~g}$ ). The PS was mixed with $430 \mathrm{~g}$ of water. The resulting slurry was continuously stirred and heated at a temperature of $55-59^{\circ} \mathrm{C}$ for $3 \mathrm{~min}$. Subsequently, the remaining portion of the water $(320 \mathrm{~g})$ was added, and the gel, through constant stirring, was heated until it began to clarify. Heating was then stopped, and the gelatinised PS was poured into a vessel with weighted HS. The mixture was manufactured with a forced-action rotary paddle mixer until a homogenous mixture was obtained. The prepared mixtures were poured into special wooden moulds that were lubricated with oil. The bottom and side parts of the moulds had holes for water evaporation during the solidification process of the bio-composites. The moulds had wood pistons

Table 2. Particle size distribution of hemp shives

\begin{tabular}{|c|c|c|c|c|c|c|c|c|c|c|}
\hline \multirow{2}{*}{ Sample } & \multicolumn{10}{|c|}{ Particle size (in $\mathrm{mm}$ ) distribution, mass \% } \\
\hline & $35-40$ & $30-35$ & $25-30$ & $20-25$ & $15-20$ & $10-15$ & $5-10$ & $1-5$ & $<1$ & Others \\
\hline HS-A & 6.15 & 4.19 & 5.64 & 4.58 & 12.77 & 16.77 & 26.88 & 16.14 & 2.00 & 4.88 \\
\hline HS-B & & & & 3.60 & 7.59 & 26.67 & 42.68 & 16.67 & 0.33 & 2.46 \\
\hline
\end{tabular}




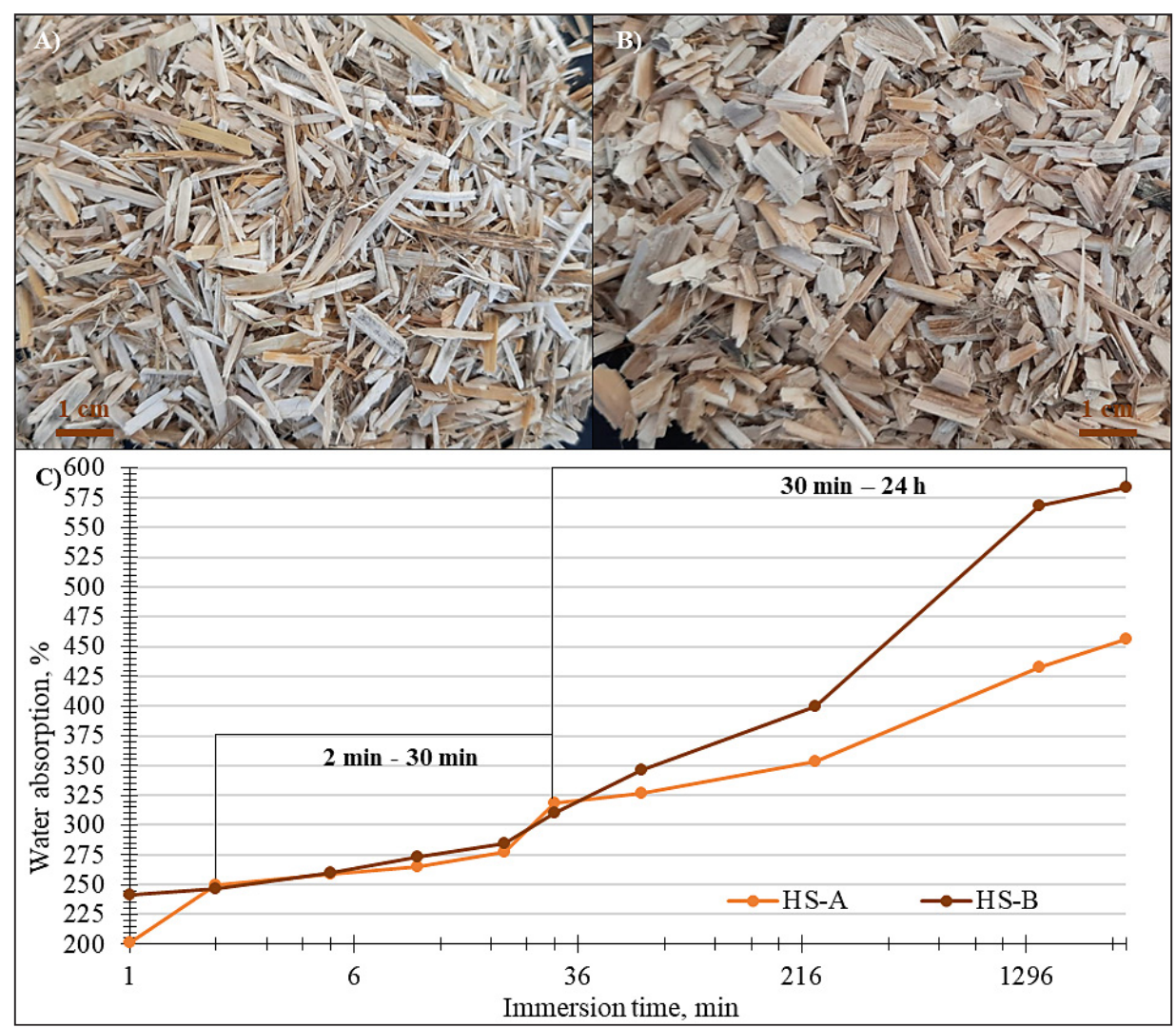

Figure 1. Hemp shives used in this study; a) macrostructure of bulk HS-A, b) macrostructure of bulk HS-B, c) kinetic water absorption behaviour

Table 3. Composition of the bio-composite mixture by weight

\begin{tabular}{|c|c|c|c|c|c|}
\hline \multirow{2}{*}{ Composition } & \multicolumn{3}{|c|}{ Components, g } & \multirow{2}{*}{ HS/PS } & \multirow{2}{*}{ PS/Water } \\
\cline { 2 - 4 } & HS & PS & Water & & \\
\hline HS-A-5.0 & 500 & 100 & 750 & 5.0 & 0.13 \\
\hline HS-A-3.3 & 500 & 150 & 750 & 3.3 & 0.20 \\
\hline HS-A-2.5 & 500 & 200 & 750 & 2.5 & 0.27 \\
\hline HS-A-2.0 & 500 & 250 & 750 & 2.0 & 0.33 \\
\hline HS-B-5.0 & 500 & 100 & 750 & 5.0 & 0.13 \\
\hline HS-B-3.3 & 500 & 150 & 750 & 3.3 & 0.20 \\
\hline HS-B-2.5 & 500 & 200 & 750 & 2.5 & 0.27 \\
\hline HS-B-2.0 & 500 & 250 & 750 & 2.0 & 0.33 \\
\hline
\end{tabular}

fitted on their upper sides to compact the mixture and provide a flat surface on each side. Thereafter, the upper parts of the moulds were placed on the surfaces of the mixture and compressed up to $80 \%$ vol. In order to maintain a steady compaction level during the drying process, the pistons were placed in a custommade clamping system, consisting of four long screws holding four pieces of wood pressed onto the piston.

\section{Testing methods}

\section{Bulk density}

The bulk density of the bio-composites was determined according to EN 1602 for plate shape specimens having the dimensions $25 \times 25 \times 5 \mathrm{~mm}$.

\section{Compressive strength}

The compressive stress at $10 \%$ and $20 \%$ deformation rates was tested according to the EN 826 method (EN 826:2013 - Thermal Insulating Products for Building Applications - Determination of Compression) by using a H10KS computerised machine in Hounsfield, Surrey, UK. The maximum loading force was $10 \mathrm{kN}$, the loading accuracy was $\pm 0.5 \%$ and the loading speed accuracy was $\pm 0.05 \%$. Six specimens were tested for each composition with the dimensions $100 \times 100 \times 70 \mathrm{~mm}$. Prior to conducting the test, the specimens were conditioned for six hours at $23 \pm 5^{\circ} \mathrm{C}$. The specimens were then aligned on the bottom support and subjected to an initial loading pressure of $250 \pm 10 \mathrm{~Pa}$. The loading speed during the tests was $0.7 \mathrm{~mm} / \mathrm{min}$. The specimens 
were compressed until a $10 \%$ deformation rate was achieved.

\section{Ultrasound pulse velocity (UPV)}

The non-destructive ultrasound pulse velocity test was chosen for evaluating the structure of the prepared bio-composite samples (de Fazio et al. 2019; Pinto et al. 2020; Fischer et al. 2019). The development of the samples with different PS/HS ratios and the structural changes in the samples were evaluated using the ultrasonic pulse velocity (UPV) method and the Pundit 7 tester. A specimen was placed between two ultrasonic transducers (transmitter and receiver) operating at $54 \mathrm{kHz}$. The transducers were pressed against the specimen at two opposite points. Vaseline was used to ensure effective contact. The ultrasonic pulse velocity was calculated using Equation (1):

$$
V=\frac{l}{\tau} \cdot 10^{6}
$$

where: $l$ is the distance between the cylindrical heads (m), and $\tau$ is the time taken for the pulse to spread (s).

\section{Damage indicator}

The structure damage was monitored through ultrasonic testing, wherein, before and after conducting the compressive strength test, the state of each sample was examined. The time needed for the pulse to travel across the sample was measured along the longitudinal direction, each time at the same sensor's location. The pulse travel times through the sample are related to the Young's moduli of the materials, and, often, the relative dynamic modulus is transformed to the damage indicator $\Omega$ (Løland 1980):

$$
\Omega=1-\left(\frac{t_{0}}{t}\right)^{2},
$$

where: $\Omega$ is the damage indicator, $t_{0}$ is the pulse travel time before conducting the compressive stress test (s) and $t$ is the pulse travel time after conducting the compressive stress test (s).

\section{Capillary water absorption}

The capillary water absorption $\left(\mathrm{kg} / \mathrm{m}^{2}\right)$ of the bio-composites was measured after solidifying the samples in an oven drying chamber by using a sample with the dimensions of $100 \times 100 \times 70 \mathrm{~mm}$. Prior to conducting the test, all the specimens were conditioned for not less than six hours at a temperature of $23 \pm 5^{\circ} \mathrm{C}$ at a relative air humidity of $50 \pm 5 \%$ (according to the EN 1609 conditioning procedure). The test was carried out according to the requirements of EN 1609 (method A). The specimens were placed on two steel bars (to ensure water absorption only on the underside of the specimens) in the empty water tank. Subsequently, sufficient load was applied to keep them partially immersed. Water was poured so that the bottom faces of specimens were $10 \pm 2 \mathrm{~mm}$ below the water surface. Two replications were performed for each mix. The purpose of this test was to simulate a capillary rising in a construction wall to assess the bio-composite behaviour towards water. The water level was maintained at $10 \mathrm{~mm}$ during the total duration of the experiment. The initial dry mass of specimens $M_{0}(\mathrm{~kg})$ was first measured. The specimens were then immersed in water for different periods of time (10 min, $30 \mathrm{~min}, 60 \mathrm{~min}, 90 \mathrm{~min}$ and 24 hours). After the immersed specimens were taken out, the excess water was allowed to drain for $1 \mathrm{~min}$ by using drainage equipment, which was inclined at $45^{\circ}$. The mass of the impregnated sample $M_{t}(\mathrm{~kg})$ was measured. Eqation (3) was used to calculate the capillary water absorption $W_{\text {cap. }}\left(\mathrm{kg} / \mathrm{m}^{2}\right)$ :

$$
W_{\text {cap. }}=\frac{M_{t}-M_{0}}{A_{p}}
$$

where: $M_{t}$ is the mass of the sample impregnated for a certain period of time $(\mathrm{kg}), M_{0}$ is the initial mass of the dry sample and $A_{p}$ is the area of the bottom surface of the sample $\left(\mathrm{m}^{2}\right)$.

\section{Water absorption by mass}

The water absorption $(W)$ by mass was tested in accordance with EN 12087 (method A) Six parallel samples of each composition with dimensions $100 \times 100 \times 70 \mathrm{~mm}$ were immersed in water for 24 hours. The percentage of water absorbed was calculated using Eq. (4):

$$
W=\frac{M_{24 h}-M_{0}}{M_{0}} \times 100 \%,
$$

where: $W$ is the water absorption by mass (\%), $M_{24 \mathrm{~h}}$ is the mass of the sample (g) following immersion in water for $24 \mathrm{~h}$ and $M_{0}$ is the mass of the dry sample $(\mathrm{g})$.

\section{Swelling in thickness}

The test of swelling in thickness was conducted according to EN 317. The initial thickness of the test specimens at the intersection of the diagonals was measured according to EN 325 . The specimens were then immersed for 24 hours with their faces lying vertical in clean and still water at 
a temperature of $20 \pm 1^{\circ} \mathrm{C}$. The temperature in the room was maintained at $20 \pm 1^{\circ} \mathrm{C}$, and the relative humidity was between $45 \%$ and $55 \%$.

The upper edges of the specimens were immersed in water up to $25 \pm 5 \mathrm{~mm}$ throughout the whole test. After the immersion time elapsed, the excess water was removed. The final thickness was determined, and the swelling in thickness was calculated. Prior to conducting the test, all the specimens were conditioned at a temperature of $20 \pm 2{ }^{\circ} \mathrm{C}$ at a relative air humidity of $65 \pm 5 \%$ until the measurements made at 24 hours intervals did not differ by more than $0.1 \%$ of the specimen mass. A conditioning procedure was carried out according to the test standard requirements. Three specimens with the dimensions of $50 \times 50 \times 12 \mathrm{~mm}$ were used for testing each composition.

\section{Thermal conductivity}

The thermal conductivity was tested for both the HS and the bio-composites. The thermal conductivity of HS was determined in accordance with EN 12667 (BS EN 12667:2001 Thermal Performance of Building Materials and Products. Determination of Thermal Resistance by Means of Guarded Hot Plate and Heat Flow Meter Methods. Products of High and Medium Thermal Resistance - European Standards). The measurements were conducted on HS that were poured into a flexible mould made of thin paper with the dimensions of $250 \times 250 \times 50 \mathrm{~mm}$ to overflowing using the scoop. The surplus was removed, and the specimen was placed on an apparatus, where it was loaded with $1000 \mathrm{kPa}$. The test was carried out using a LaserComp FOX 304 computerised testing machine, which has measurement limits from $0.01 \mathrm{~W} /(\mathrm{m} \cdot \mathrm{K})$ to $0.50 \mathrm{~W} /(\mathrm{m} \cdot \mathrm{K})$ and a measuring accuracy of $\sim 1 \%$. The difference between the measuring plates was $20^{\circ} \mathrm{C}$, and the average test temperature was $10^{\circ} \mathrm{C}$. For the tests, three samples of each composition were formed. Prior to performing the test, the aggregate was dried at a temperature of $110 \pm 5^{\circ} \mathrm{C}$ (according to the EN 1097-3 procedure).

Thermal conductivity of the bio-composite boards from the HS and the corn starch was tested on three samples with dimensions $250 \times 250 \times 12 \mathrm{~mm}$. The same apparatus was used for conducting this test as that used for measuring the thermal conductivity of loose HS. Prior to taking the measurements, the test samples were dried in a ventilated drying oven at $70^{\circ} \mathrm{C}$ to a constant mass (the difference between the two weightings measured at 24-hour intervals was $<0.1 \%$ ) and then conditioned to a constant mass for not less than 72 hours to attain equilibrium at a temperature of $23 \pm 5^{\circ} \mathrm{C}$ at a relative air humidity of 50 $\pm 5 \%$. In order to determine the moisture content absorbed during the measurements, the specimens were weighted before and after determining the thermal conductivity.

\section{RESULTS AND DISCUSSIONS}

In this study, the bio-composite samples of eight different compositions have been prepared and studied (Table 3). Figure 2 shows the obtained samples of both series (with hemp shives A and with hemp shives B, respectively) with highest and lowest hemp shives/potatoes starch ratio.

\section{Bulk density}

In order to evaluate the impact of HS on the physical and mechanical properties of the final product and to select the optimal HS/PS ratio, four compositions with each type of HS and different

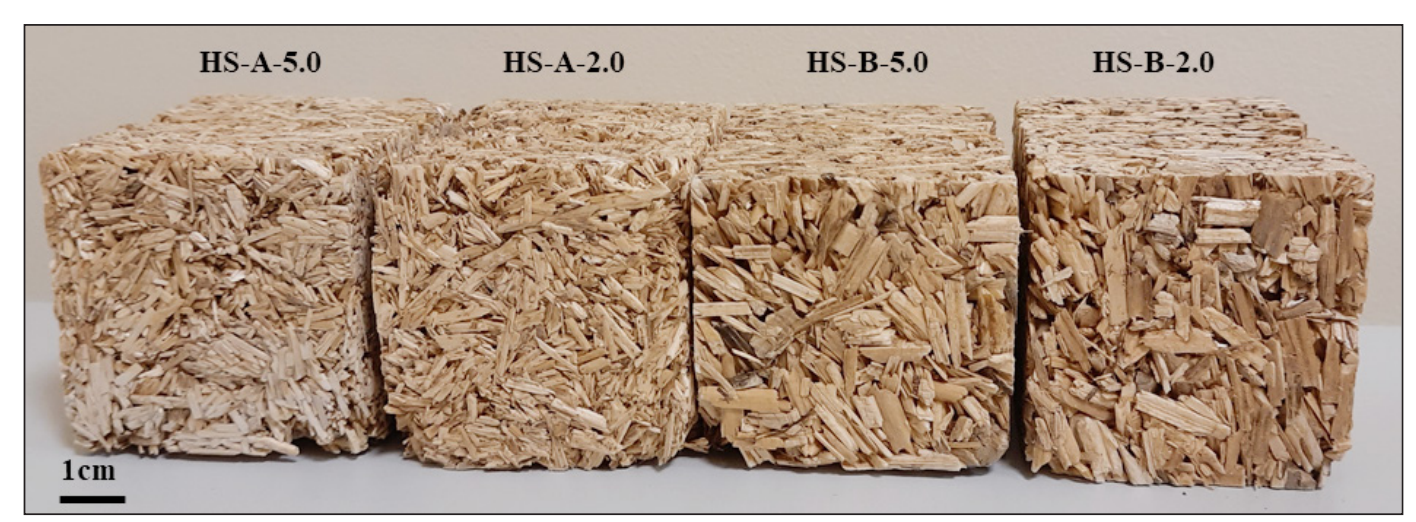

Figure 2. Obtained bio-composites bonded by starch binder 
HS/PS ratios were prepared. It can be noticed that the process of preparing the composition with the $\mathrm{PS} /$ water ratio greater than 0.2 became complicated; preparing a sample with the maximal PS/water ratio of 0.33 was difficult. These findings agree with (Le et al. 2014b). The study proved that by increasing the PS/water ratio (from 0.1 to 0.25 ), the binder solution density increases from $1,010 \mathrm{~kg} / \mathrm{m}^{3}$ to $1,150 \mathrm{~kg} / \mathrm{m}^{3}$, and, as a consequence, the viscosity of the solution increases by up to 2.5 times.

The effects of the HS/PS ratio on the density of the bio-composites are noticed in Figure 3. It can be seen that the density of both the HS type samples increases with a decrease in the HS/PS ratio. The densities of the compositions differ depending on the type of HS and the aspect ratio: the density of the compositions with HS-B type, with a low aspect ratio (having no particles with dimensions from $25-40 \mathrm{~mm}$ ), is $7.0-5.6 \%$ higher than the same composition sample with HS-A type (which also has particles with dimensions ranging from $25 \mathrm{~mm}$ to $40 \mathrm{~mm}$ and a high aspect ratio). This difference in density can be attributed to the different particle sizes of HS: longer particles can influence the packing density with greater number of voids and can lead to low densities of bio-composites. When the HS/PS ratio decreases from 5 to 2 , the density of the bio-composites increases by $21 \%$ (HS-A) and $20 \%$ (HS-B). A similar effect is observed in the bio-composites made from both types of HS. This indicates that the particle size of the HS does not affect the phenomena, which depends on the HS/PS ratio due to an improved interaction of HS with a greater PS quantity.

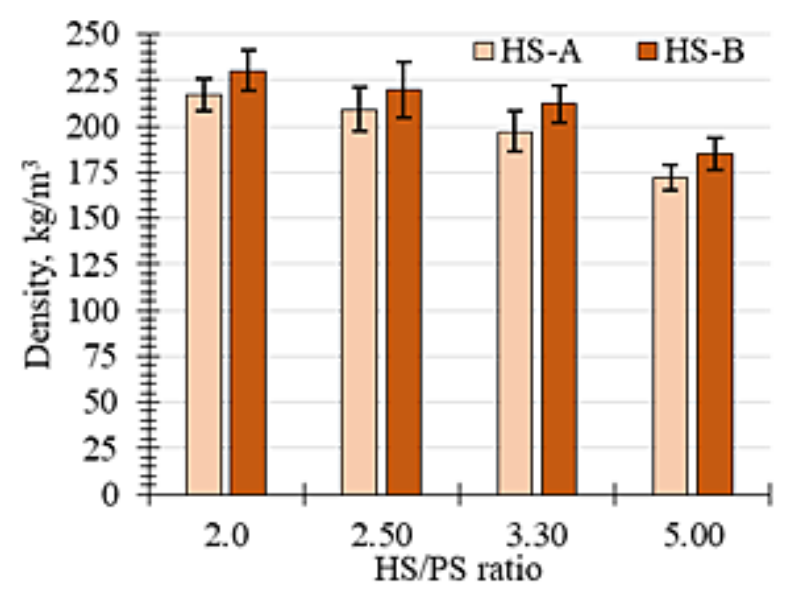

Figure 3. The bulk density of biocomposites depending on the HS type and the HS/PS ratio in the composition

\section{Compressive strength}

The compressive strength of bio-composites was obtained for $10 \%$ and $20 \%$ longitudinal strains (Figure 4). The compressive strength was tested in a similar manner to other thermal insulation materials, and the majority of the thermal insulating materials under compression do not show a noticeable fracture limit (i.e. specimens do not fracture but densify). Compression does not lead to the failure of the specimen; however, it induces a continuous increase in stress in the specimen. It was observed that the variation in compressive strength does not lead to the failure of the studied sample. The compressive strength of the samples with HS-A (Figure 4) increases from 0.49 MPa (HS-A-5.0) to $1.2 \mathrm{MPa}$ (HS-A-2.0) at $10 \%$ strain. The compressive strength of the samples with HS-B increases from 0.47 $\mathrm{MPa}$ (HS-B-5.0) to 1.5 $\mathrm{MPa}$ (HS-B2.0). The influence of the HS aspect ratio on the mechanical properties is also evident: the samples with HS having a low aspect ratio demonstrate improved mechanical properties.

Decreasing the HS/PS ratio from 5 to 3.3 causes an increase in the compressive strength of the samples by $34 \%$ (in HS-A) and by $42 \%$ (in HS-B). Overall, it can be observed that if the HS/ PS ratio decreases from 5 to 2 , the compressive strength increases more than twice in HS-A and more than three times in HS-B.

At $20 \%$ strain, the compressive strength of the samples (Figure 4) increases along similar lines. The results indicate that when the HS/PS ratio is reduced, the compressive strength of the HS-A type samples increases from $0.59 \mathrm{MPa}$ to 1.4 MPa. For the HS-B type samples, when the $\mathrm{HS} / \mathrm{PS}$ ratio is reduced, the compressive strength of the samples increases from $0.56 \mathrm{MPa}$ to 1.7 MPa. The compressive strength of the HS-B type samples is visibly higher compared to the HS-A HS samples.

The compressive strength of the prepared composites seemed to vary with respect to the density, which indicates that the impact of density variation on the compressive strength of starch-hemp is significant. When the density increases, so does the compressive strength. Consequently, the mechanical properties of the samples can be controlled by the HS/PS ratio and the HS aspect ratio. In general, the prepared lightweight bio-composites revealed enhanced mechanical properties. The composites could withstand the compressive stresses ranging from $0.47 \mathrm{MPa}$ 


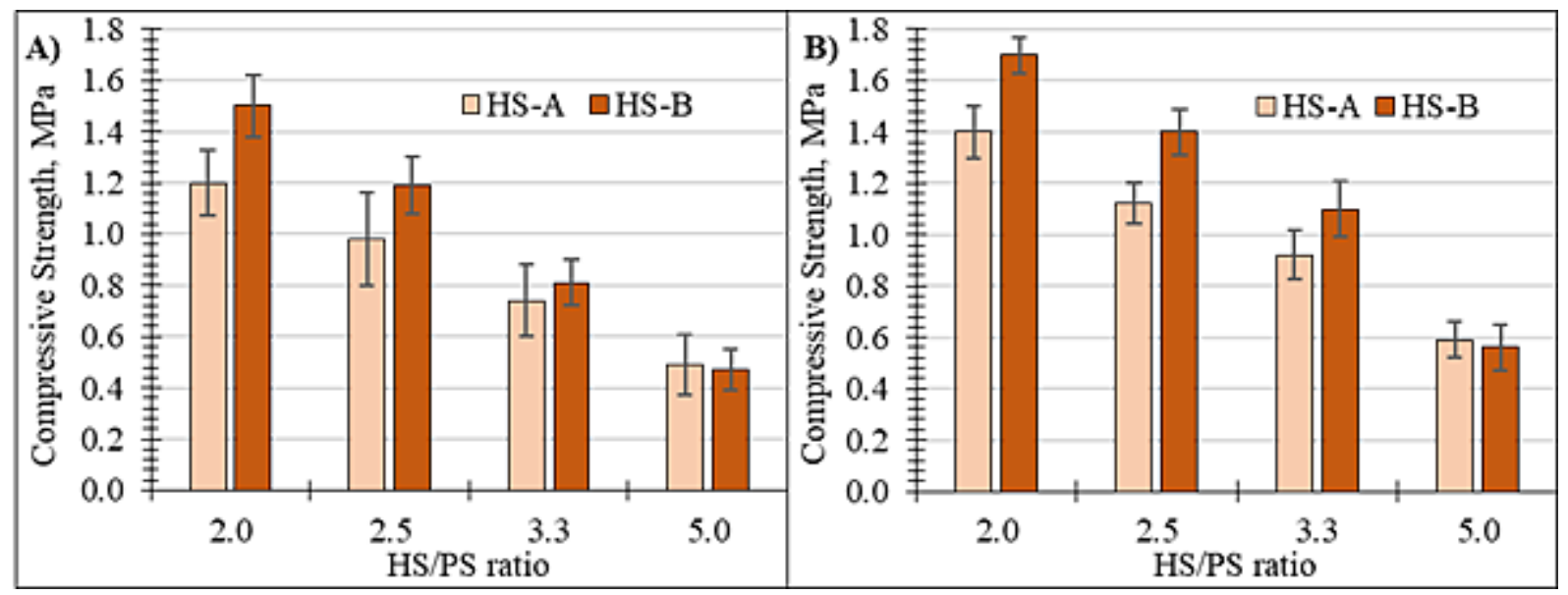

Fig. 4. The compressive strengths of bio-composites depending on the HS type and the HS/PS ratio in the composition. A) at $10 \%$ strain and B) at $20 \%$ strain

to $1.5 \mathrm{MPa}$ at very low densities $(172-230 \mathrm{~kg}$ / $\mathrm{m}^{3}$ ). This was relatively better compared to other HS-based composites, such as hemp-lime (0.02$0.39 \mathrm{MPa}$ at a density of $360 \mathrm{~kg} / \mathrm{m}^{3}$ ) (Walker et al. 2014), hemp-clay (0.39 MPa at a density of $373 \mathrm{~kg} / \mathrm{m}^{3}$ ) (Mazhoud et al. 2017), hemp-starch $\left(0.4 \mathrm{MPa}\right.$ at a density of $\left.177 \mathrm{~kg} / \mathrm{m}^{3}\right)$ (Sandrine et al. 2015) and a hemp bio-based binder based centred around a starch derivative and a crosslinker $(0.49-1.05 \mathrm{MPa}$ at a density of $175-240 \mathrm{~kg} /$ $\left.\mathrm{m}^{3}\right)$ (Hussain et al. 2019).

The higher the HS/PS ratio (5.0), the smaller the effect of the HS dimensions on the compressive performance. A linear relationship was noticed (10\% and $20 \%$ in both cases). The biocomposites with longer shive particles have significantly lower compressive strengths than the bio-composites with shorter shive particles (if the HS/PS is low, ratio of 2.0). When the HS/PS ratio increases to 5.0, the effect of HS size on the compressive strength of the bio-composite remains insignificant.

\section{Ultrasound pulse velocity (UPV) and damage indicator calculations}

The development of the bio-composite structure was tested by UPV and is presented in Figure 5. As observed in Figure 5, there is a relationship between the HS/PS ratio and the UPV values. When the HS/PS ratio is reduced, the density of the samples increases, and the structure of the samples becomes more homogenous. A greater quantity of PS binder ensures cohesion and improves contact between the binder and the hemp particle.

When the HS/PS ratio in the HS-A samples decreases, the UPV values increase from $420 \mathrm{~m} / \mathrm{s}$ to $740 \mathrm{~m} / \mathrm{s}$. In the HS-B samples, the UPV values increase from $401 \mathrm{~m} / \mathrm{s}$ to $789 \mathrm{~m} / \mathrm{s}$, and the HS/PS ratio decreases, which proves that UPV depends
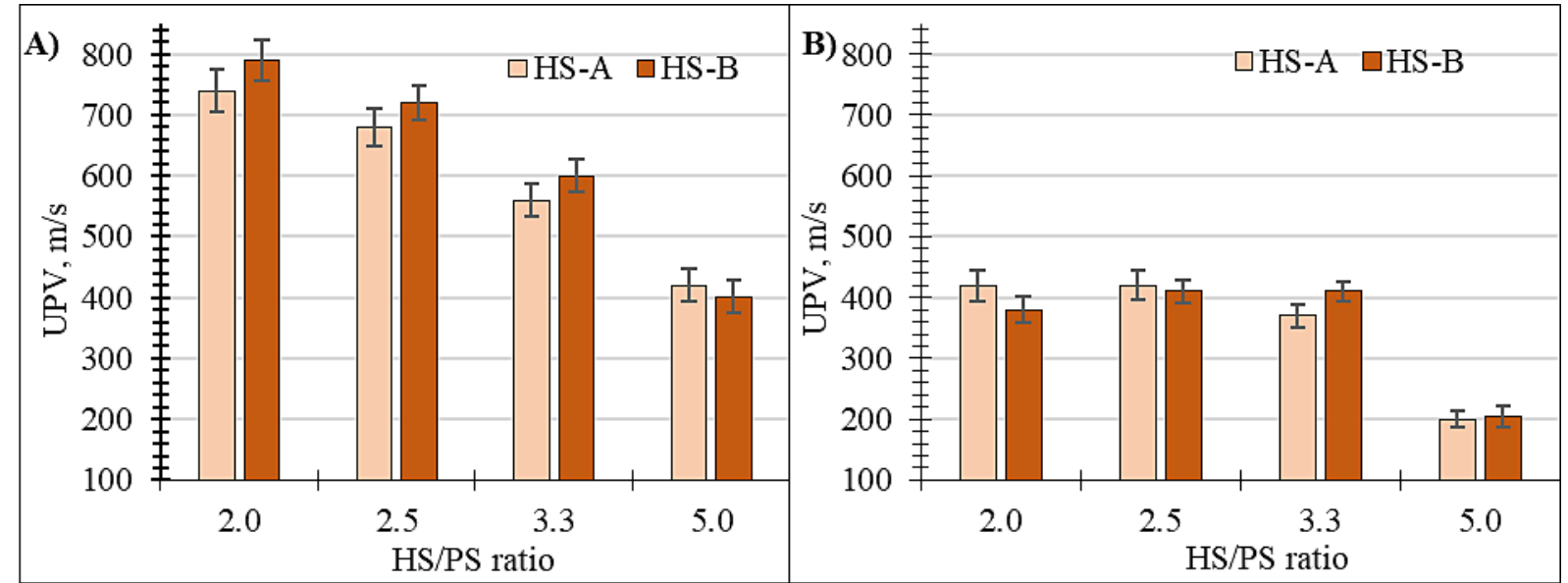

Figure 5. The UPV of bio-composites depending on the HS type and the HS/PS ratios in the composition. A) measured before compressive strength testing and B) measured after compressive strength testing 
on the HS/PS ratio. The UPV value for the samples made of HS with longer dimensions increases by 1.75 times with a corresponding reduction in HS/ PS ratio from 5 to 2. A similar effect is observed for the samples without longer HS in the composition: the UPV value increases by two times if HS/ PS ratio decreases from 5 to 2 . It can also be seen that when the proportion of PS is higher (and the HS/PS ratio is lower) in the composition, the hemp particles are better coated by the binder during the manufacturing process. Following the compressive strength test, the UPV value changes in the samples, which enables the evaluation of the structural damage in the samples after loading (Figure 6). A damaged structure is mainly observed for the samples with the highest HS/PS ratios and for HS-B type samples with the lowest HS/PS ratios. For HS-A type samples, when the HS/PS ratio is reduced from 5.0 to 2.0, the UPV values decrease by $52.4 \%, 33.9 \%, 38.23 \%$ and $43.24 \%$. For HS-B type samples, the UPV values decrease by $48.8 \%$, $31.6 \%, 43.05 \%$ and $51.83 \%$. It can be concluded that the bio-composites made from the HS with longer particles are less prone to destruction, and this is a serious argument in favour of using the HS with longer particles and higher aspect ratios.

The damage indicator calculations (Figure 6) indicate that at HS/PS ratios of 5 and 2, the structure of the sample is more damaged. It can be assumed that the structure will be less damaged when the HS/PS ratio varies between 3.3 and 2.5. It can also be concluded that the cohesion between the fibres and the matrix will be better. In general, the UPV test confirms the density and the compressive strengths of the bio-composite. This test can be employed for determining the non-destructive characterisation of bio-composites.

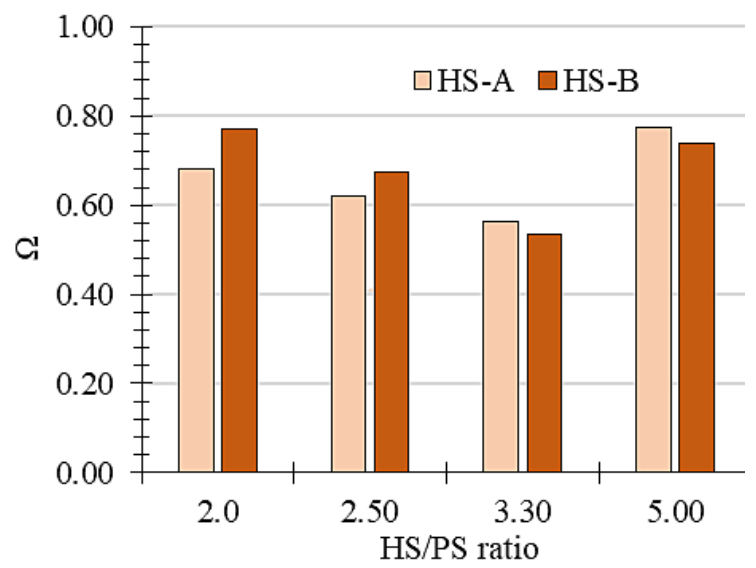

Figure 6. The damage indicator calculated for bio-composites after compressive strength testing

\section{Capillary water absorption and water absorption by mass}

The kinetics of capillary water absorption, measured through sequential weighting after water immersion during different time intervals, of the HS-A and HS-B samples is presented in Figure 7. The results of the test performed reveal that the kinetics of capillary water absorption depends on the HS/PS ratio.

The HS-A samples with the HS/PS ratio varying from 2.0 to 5.0 absorb, through the surface, over $39-42 \%$ of their maximum capillary absorption capacity in the first ten minutes. During the first ten minutes, the analogous composition of the HS-B samples absorbs $40-46 \%$ of the maximum capacity. Thus, it can be argued that the aspect ratio (Table 1) of HS and the surface nature (Figure 1) influence capillary water absorption (Figure 7). During the next 30-90 min, the capillary water absorption, in each of the

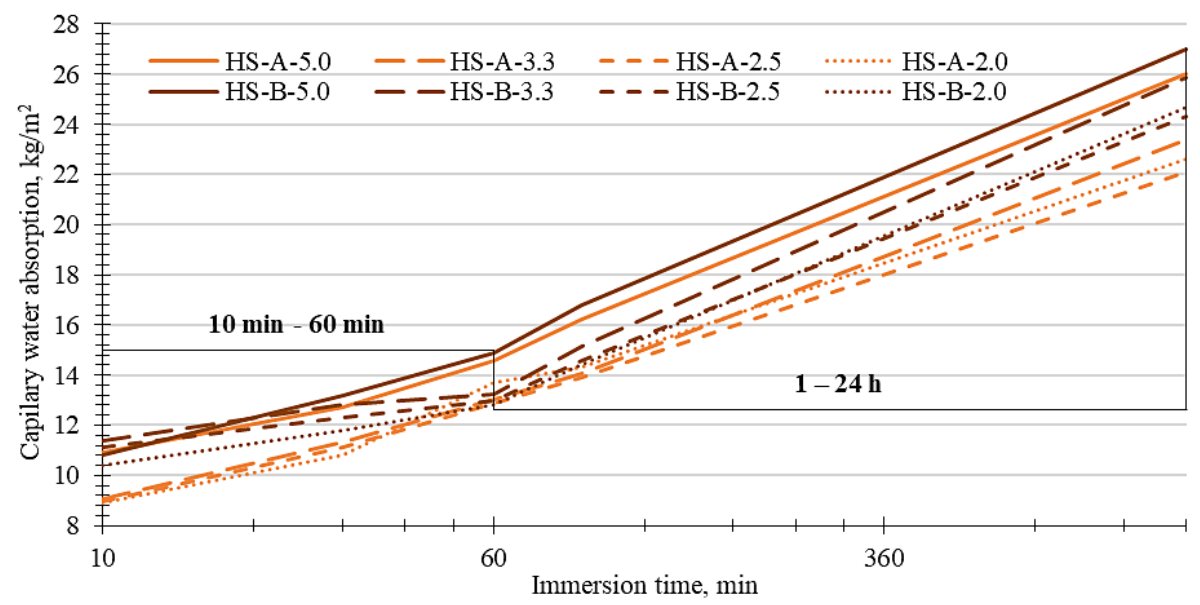

Figure 7. Capillary water absorption of the examined bio-composites 
compositions, increases. However, by decreasing the HS/PS ratio, the capillary water absorption capacity decreases. When the duration of water immersion increases by up to 24 hours, the difference between the samples depending on the HS/ PS ratio increases as well. By decreasing the HS/ PS ratio till 2.5, the capillary water absorption rate decreases from $26.1 \mathrm{~kg} / \mathrm{m}^{2}$ to $22.3 \mathrm{~kg} / \mathrm{m}^{2}$ (in the HS-A samples) and from $27.0 \mathrm{~kg} / \mathrm{m}^{2}$ to $23.3 \mathrm{~kg} /$ $\mathrm{m}^{2}$ (in HS-B samples). The difference in the quantity of water absorbed between the samples with the lowest and the highest PS/HS ratios can be explained by the lower hydrophilicity of the samples with higher quantities of PS in the composition (Kremensas et al. 2019; Le et al. 2014b).

According to the water absorption by mass results (Figure 8), it is obvious that when the quantity of PS in the composition increases, the water absorption capacity decreases. During the 24-hour period, the bio-composites examined absorbed $150-190 \%$ of their initial mass depending on the composition. As observed from Figure 8, the bio-composites with HS-A show lower water absorption capacities compared to the bio-composites with HS-B. A different particle size distribution causes the water absorption capacity of bio-composites with HS-B to increase. As HS-B comprise smaller particles than HS-A (Table 2), HS-B particles can easily absorb water in their inner structures.

The capillary water absorption occurs very quickly in the samples with the highest HS/PS ratios for both the sample types, HS-A and HS-B. The water absorption can be divided into two periods. During the first period, surface absorption occurs, which causes the sample weight to rapidly increase. This behaviour reflects the rapid nature

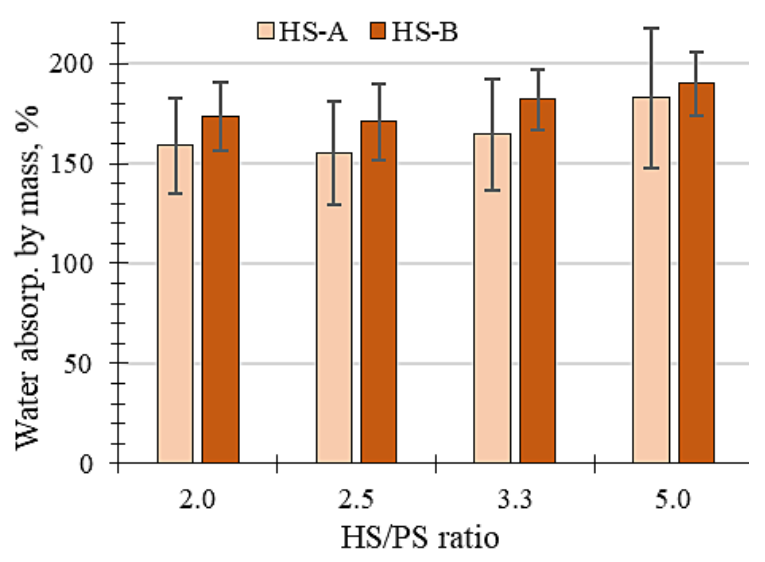

Figure 8. Water absorption by mass of the examined bio-composites of the wetting of hemp particles. In the second period, the slow absorption into the hemp particle structure occurs. This demonstrates the diffusive behaviour of water propagation in the structure up to 24 hours.

\section{Swelling in thickness}

Apart from the capillary water absorption test, the dimensional changes in thickness are another important parameter of bio-composites. Due to the impact of water, a swelling process takes place, during which particles enlarge and internal stress occurs. This affects the contact zones between the particles. Following water immersion, the data pertaining to the swelling in thickness of the bio-composite samples is indicated in Figure 9. The lowest capillary water absorption capacity was observed in the samples with low HS/PS ratios. However, the lowest swelling in thickness was observed in the samples with high HS/PS ratios (ratio of 5), where the swelling in thickness was $8.75 \%$ (in HS-A-5.0) and $8.87 \%$ (in HS-B-5.0). When the HS/PS ratio reduces, the swelling in thickness increases up to $9.45 \%$ (in bio-composites with HS-A) and up to $9.60 \%$ (in bio-composites with HS-B).

Amylose chains pass into the aqueous phase and tend to inhibit the swelling of starch granules. Thus, the leaching of amylose facilitates water percolation into the starch particles and improves their short-term water absorption capacities (Hedayati and Niakousari 2018). It can be assumed that the layer thickness between the HS is small, which leads to stress and contributes to the swelling action of the particles. HS mainly consist of polymer compounds, which attract water through

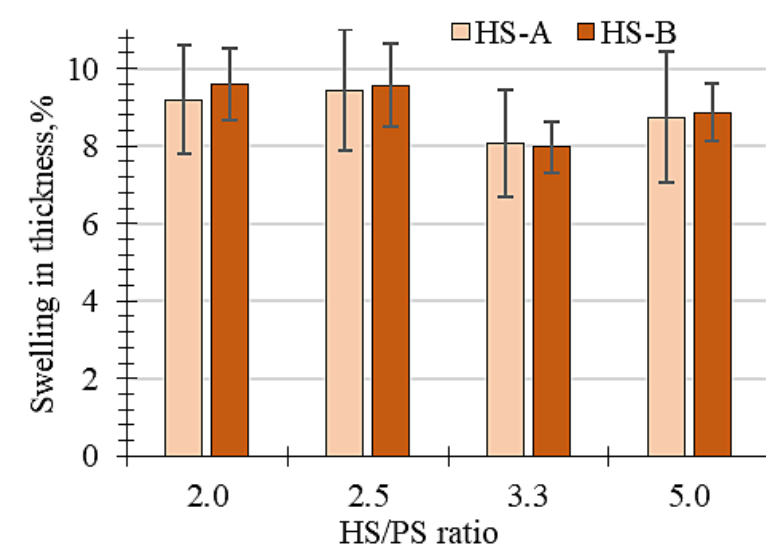

Figure 9. Swelling in thickness according to the HS/PS ratios in the samples with HS-A and HS-B 
hydrogen bonds. Therefore, the volume of the HS wall increases proportionally to the volume of water attracted. As indicated in (Baishya and Maji 2018), if the PS quantity in the composition is greater when the water penetrates into the samples, the starch particles begin to swell, and the unbounded starch molecules (which are mainly the amylose chains) pass into the aqueous phase, thereby increasing the solubility and contributing to the changes in the sample dimensions.

\section{Thermal conductivity}

The thermal conductivity was determined to clarify the impact of the HS size and type and the HS/PS ratio on the thermal properties of the bio-composites (Figure 10). It can be observed that there is a significant relationship between the thermal conductivity and the HS/PS ratio in the composition. When the HS/PS ratio is the highest, and the density of the bio-composite is the lowest, the thermal conductivity coefficient is $0.060 \mathrm{~W} /(\mathrm{m} \cdot \mathrm{K})$ for HS-A and $0.059 \mathrm{~W} /(\mathrm{m} \cdot \mathrm{K})$ for HS-B. Kremensas et al. (2019) suggested that the changes in the thermal conductivity coefficient can be explained by the increasing amount of heat transfer that occurs through the solid frame and the low alteration in heat transfer that takes place through air when the density of the composite increases. Greater number of finer particles, which can partially fill up the voids, enable improved interaction between the HS particles and PS (Baishya and Maji 2018). These findings were compatible with the study conducted by Kremensas et al. (2019). Compared to larger particles, smaller voids and air gaps are formed

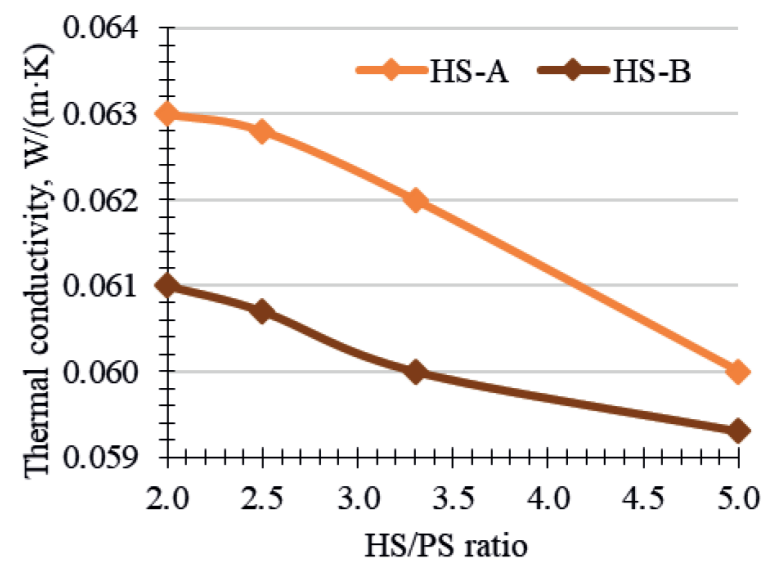

Figure 10. The thermal conductivity coefficient according to the HS/PS ratio in the HS-A and HS-B samples between smaller HS particles, through which lower amount of heat exchange occurs due to the heat transfer taking place through air.

As per the results obtained from this study, it can be stated that the differences between the results of the thermal conductivity coefficient of the bio-composite are relatively small, but the impact of the chosen HS is significant and can be observed.

\section{CONCLUSIONS}

In this study, two types of HS have been used and investigated as aggregates for bio-composites, namely HS-A (with the max length of 40 $\mathrm{mm}$ ) and HS-B (with the max length of $20 \mathrm{~mm}$ ) with aspect ratios ranging from 2.9 to 16.3 (for HS-A) and from 1.0 to 7.8 (for HS-B). The main properties of HS were determined. The results indicated that the density of both HS varies a little, whereas the water absorption capacity of the HS, following water immersion for a time period of 30 min -24 hours differs by $22 \%$. The thermal conductivity of HS-A (with a higher aspect ratio) is lower and reaches $0.045 \mathrm{~W} /(\mathrm{m} \cdot \mathrm{K})$; however, with HS-B (having a lower aspect ratio), the thermal conductivity was found to be higher at $0.048 \mathrm{~W} /(\mathrm{m} \cdot \mathrm{K})$.

It can be concluded that using a lower aspect ratio (HS-B containing smaller particles) in biocomposites enhances the mechanical properties by about $15 \%$, densifies the structure by $7 \%$, increases the water absorption capacity and swelling in thickness by $7 \%$ and $4.4 \%$, respectively, decreases the thermal conductivity by $3.2 \%$ and increases the density by $4.3 \%$.

The properties of bio-composites bonded with PS at different HS/PS ratios were also investigated. It can be concluded that the aspect ratio (granulometry) of HS and the HS/PS ratio directly affect the mechanical properties, density, water absorption behaviour and the thermal properties of the resulting bio-composite.

Regardless of the aspect ratio used in HS, reducing the HS/PS ratio from 5.0 to 2.0 decreases the water absorption capacity from $190 \%$ to $155 \%$. However, the following properties simultaneously showed an increase:

- the density increased from $172 \mathrm{~kg} / \mathrm{m}^{3}$ to $230 \mathrm{~kg} / \mathrm{m}^{3}$,

- the compressive stress at $10 \%$ deformation rate increased from $0.47 \mathrm{MPa}$ to $1.4 \mathrm{MPa}$, 
- the compressive stress at $20 \%$ deformation rate increased from $0.56 \mathrm{MPa}$ to $1.7 \mathrm{MPa}$,

- the UPV values increased from $400 \mathrm{~m} / \mathrm{s}$ to $790 \mathrm{~m} / \mathrm{s}$ in the chosen samples,

- the thermal conductivity values increased from $0.059 \mathrm{~W} /(\mathrm{m} \cdot \mathrm{K})$ to $0.063 \mathrm{~W} /(\mathrm{m} \cdot \mathrm{K})$,

- the swelling in thickness increased from $8.75 \%$ to $9.6 \%$.

In terms of the HS aspect ratio, it can be concluded that the higher the HS/PS ratio (ratio of 5.0), the smaller the impact of the HS aspect ratio on the compression strength values. A linear relationship (at 10\% and 20\% deformation rates in both cases) was observed in the bio-composites with higher aspect ratios having significantly lower compressive strengths than in the bio-composites with lower aspect ratios (when the HS/PS ratio was low, 2.0-3.0). The results indicated that bio-composites made from HS with higher aspect ratios and relatively longer particle lengths are less prone to destruction. This is a serious argument in favour of using HS with longer particle lengths in the construction industry.

Preparing bio-composites with lower HS/PS ratios (ratio of 2.0) will lead to significant benefits: the mechanical properties of bio-composites will be enhanced by up to three times compared to preparing the bio-composites with higher HS/ PS ratios (ratio of 5.0).

\section{Acknowledgement}

Publication is created with support of European Regional Development Fund project "A new concept for low-energy eco-friendly house", Grant Agreement No 1.1.1.1/19/A/017.

\section{REFERENCES}

1. Alhaik G., Dubois V., Wirquin E., Leblanc A., Aouad G. 2018. Evaluate the influence of starch on earth/hemp or flax straws mixtures properties in presence of superplasticizer. Construction and Building Materials, 186, 762-772. https://doi. org/10.1016/j.conbuildmat.2018.07.209

2. Ashok A., Abhijith R., Rejeesh C.R. 2018. Material characterization of starch derived bio degradable plastics and its mechanical property estimation. In Materials Today: Proceedings. Elsevier Ltd. 5, 21632170. https://doi.org/10.1016/j.matpr.2017.09.214

3. Avérous L. 2004. Biodegradable multiphase systems based on plasticized starch: A review. Journal of Macromolecular Science - Polymer Reviews.
Taylor \& Francis Group. https://doi.org/10.1081/ MC-200029326

4. Baishya P., Maji T.K. 2018. A Comparative study on the properties of graphene oxide and activated carbon based sustainable wood starch composites. International Journal of Biological Macromolecules, 115, 970-977. https://doi.org/10.1016/j. ijbiomac.2018.04.192

5. Balčiunas G., Vejelis S., Vaitkus S., Kairyte A. 2013. Physical properties and structure of composite made by using hemp hurds and different binding materials. Procedia Engineering, 57, 159-166. https://doi. org/10.1016/j.proeng.2013.04.023

6. Bénézet J.C., Stanojlovic-Davidovic A., Bergeret A., Ferry L., Crespy A. 2012. Mechanical and physical properties of expanded starch, reinforced by natural fibres. Industrial Crops and Products, 37(1), 43540. https://doi.org/10.1016/j.indcrop.2011.07.001

7. Sandrine B., Umurigirwa, Vroman I., Hoang M.T., Maalouf C. 2015. Influence of chemical modification on hemp-starch concrete. Construction and Building Materials, 81, 208-215. https://doi. org/10.1016/j.conbuildmat.2015.02.045

8. Bergeret A., Benezet J.C. 2011. Natural fibre-reinforced biofoams. International Journal of Polymer Science 2011. https://doi.org/10.1155/2011/569871

9. Bourdot A., Moussa T., Gacoin A., Maalouf C., Vazquez P., Thomachot-Schneider C., Bliard C., et al. 2017. Characterization of a hemp-based agromaterial: influence of starch ratio and hemp shive size on physical, mechanical, and hygrothermal properties. Energy and Buildings, 153, 501-512. https://doi.org/10.1016/j.enbuild.2017.08.022

10. BS EN 622-4:2019 Fibreboards. Specifications Requirements for Softboards - European Standards. n.d. Accessed May 26, 2021. https://www.en-standard.eu/bs-en-622-4-2019-fibreboards-specifications-requirements-for-softboards/

11. BS EN 12667:2001 Thermal Performance of Building Materials and Products. Determination of Thermal Resistance by Means of Guarded Hot Plate and Heat Flow Meter Methods. Products of High and Medium Thermal Resistance - European Standards. n.d. Accessed May 27, 2021. https:// www.en-standard.eu/bs-en-12667-2001-thermalperformance-of-building-materials-and-productsdetermination-of-thermal-resistance-by-means-ofguarded-hot-plate-and-heat-flow-meter-methodsproducts-of-high-and-medium-thermal-resistan ce/?gclid=Cj0KCQjwhr2FBhDbARIsACjwLo1 pb8NrtU8p6ioZmL1LkJ1QyFoZK8Y-qush6anNv1B59IbEQqtNMCoaAt6REALw_wcB

12. Cigasova J., Stevulova N., Junak J. 2013. Influence of binder nature on properties of lightweight composites based on hemp hurds. International Journal of Modern Manufacturing Technologies, 5. 
13. Collet F., Marjorie B., Serres L., Miriel J. 2008. Porous Structure and Water Vapour Sorption of HempBased Materials. Construction and Building Materials, 22 (6), 1271-1280. https://doi.org/10.1016/j. conbuildmat.2007.01.018

14. Collet F., Chamoin J., Pretot S., Lanos C. 2013. Comparison of the Hygric Behaviour of Three Hemp Concretes. Energy and Buildings, 62, 294303. https://doi.org/10.1016/j.enbuild.2013.03.010

15. Delville J., Joly C., Dole P., Bliard C. 2003. Influence of photocrosslinking on the retrogradation of wheat starch based films. Carbohydrate Polymers, 53(4), 373-381. https://doi.org/10.1016/ S0144-8617(03)00141-3

16. Dicker M.P.M., Duckworth P.F., Baker A.B., Francois G., Hazzard M.K., Weaver P.M. 2014. Green Composites: A Review of Material Attributes and Complementary Applications. Composites Part A: Applied Science and Manufacturing. https://doi. org/10.1016/j.compositesa.2013.10.014

17. EN 826:2013 - Thermal Insulating Products for Building Applications - Determination of Compression. (Accessed: May 27, 2021). https://standards.iteh.ai/catalog/standards/ cen/f54055a6-cacc-4d69-b85a-b190aea8ed7f/ en-826-2013

18. Fazio D.D., Cuomo S., Boccarusso L., Pinto F., Durante M., Meo M. 2019. Design and characterization of hybrid hemp/carbon laminates with improved impact resistance. Materials Today: Proceedings, 34, 194-201. https://doi.org/10.1016/j. matpr.2020.02.732

19. Balthasar F., Sarasini F., Tirillò J., Touchard F., Chocinski-Arnault L., Mellier D., Panzer N., et al. 2019. Impact Damage Assessment in Biocomposites by Micro-CT and Innovative Air-Coupled Detection of Laser-Generated Ultrasound. Composite Structures, 210, 922-931. https://doi.org/10.1016/j. compstruct.2018.12.013

20. Follain N., Joly C., Dole P., Bliard C. 2005. Mechanical Properties of Starch-Based Materials. I. Short Review and Complementary Experimental Analysis. Journal of Applied Polymer Science, 97(5), 1783-1794. https://doi.org/10.1002/app.21664

21. Gironès J., López J.P., Mutjé P., Carvalho A.J.F., Curvelo A.A.S., Vilaseca F. 2012. Natural FiberReinforced Thermoplastic Starch Composites Obtained by Melt Processing. Composites Science and Technology, 72(7), 858-863. https://doi. org/10.1016/j.compscitech.2012.02.019

22. Hedayati S., Niakousari M. 2018. Microstructure, Pasting and Textural Properties of Wheat Starch-Corn Starch Citrate Composites. Food Hydrocolloids, 81, 1-5. https://doi.org/10.1016/j. foodhyd.2018.02.024

23. Hussain A., Calabria-Holley J., Lawrence M.,
Yunhong Jiang. 2019. Hygrothermal and Mechanical Characterisation of Novel Hemp Shiv Based Thermal Insulation Composites. Construction and Building Materials, 212, 561-568. https://doi. org/10.1016/j.conbuildmat.2019.04.029

24. Jiang Y., Lawrence M., Hussain A., Ansell M., Walker P. 2019. Comparative moisture and heat sorption properties of fibre and shiv derived from hemp and flax. Cellulose 26(2), 823-843. https:// doi.org/10.1007/s10570-018-2145-0

25. Kairyte A., Vaitkus S., Kremensas A., Kairyte A., Vèjelis S. 2018. Physical-mechanical properties of composites from hemp shives and starch odontogenic maxillary sinusitis view project physical-mechanical properties of composites from hemp shives and starch. www.ijesi.org||Volumewww.ijesi.org

26. Hamzé K., Maalouf C., Bliard C., Gacoin A., Wakil N.E., Polidori G. 2019. Characterization of BeetPulp Fiber Reinforced Potato Starch Biopolymer Composites for Building Applications. Construction and Building Materials, 203, 711-721. https://doi. org/10.1016/j.conbuildmat.2019.01.127

27. Kremensas A., Kairyte A., Vaitkus S., Vejelis S., Balčiunas G. 2019. Mechanical Performance of Biodegradable Thermoplastic Polymer-Based Biocomposite Boards from Hemp Shivs and Corn Starch for the Building Industry. Materials. https://doi. org/10.3390/ma12060845

28. Kremensas A., Kairytė A., Vaitkus S., Vejjelis S., Członka S., Strąkowska A. 2019. The Impact of Hot-Water-Treated Fibre Hemp Shivs on the Water Resistance and Thermal Insulating Performance of Corn Starch Bonded Biocomposite Boards. Industrial Crops and Products, 137, 290-299. https://doi. org/10.1016/j.indcrop.2019.05.031

29. Kremensas A., Stapulioniene R., Vaitkus S., Kairyte A. 2017. Investigations on Physical-Mechanical Properties of Effective Thermal Insulation Materials from Fibrous Hemp. Procedia Engineering. 172, 586-594. https://doi.org/10.1016/j. proeng.2017.02.069

30. Le A.T., Gacoin A., Li A., Mai T.H., Rebay M., Delmas Y. 2014a. Experimental investigation on the mechanical performance of starch-hemp composite materials. Construction and Building Materials 61, 106-113. https://doi.org/10.1016/j. conbuildmat.2014.01.084

31. Le A.T., Gacoin A., Li A., Mai T.H., Rebay M., Delmas Y. 2014b. Experimental Investigation on the Mechanical Performance of Starch-Hemp Composite Materials. Construction and Building Materials 61, 106-113. https://doi.org/10.1016/j. conbuildmat.2014.01.084

32. Le A.T., Gacoin A., Li A., Mai T.H., Wakil N.E. 2015. Influence of Various Starch/Hemp Mixtures on Mechanical and Acoustical Behavior of 
Starch-Hemp Composite Materials. Composites Part B: Engineering, 75, 201-211. https://doi. org/10.1016/j.compositesb.2015.01.038

33. Liu Y., Chen J., Luo S., Li C., Ye J., Liu C., Gilbert R.G. 2017. Physicochemical and Structural Properties of Pregelatinized Starch Prepared by Improved Extrusion Cooking Technology. Carbohydrate Polymers, 175, 265-272. https://doi.org/10.1016/j. carbpol.2017.07.084

34. Løland K.E. 1980. Continuous Damage Model for Load-Response Estimation of Concrete. Cement and Concrete Research, 10(3), 395-402. https:// doi.org/10.1016/0008-8846(80)90115-5

35. Mazhoud B., Collet F., Pretot S., Lanos C. 2017. Mechanical Properties of Hemp-Clay and Hemp Stabilized Clay Composites. Construction and Building Materials, 155, 1126-1137. https://doi. org/10.1016/j.conbuildmat.2017.08.121

36. Pickering K.L., Aruan Efendy M.G., Le T.M. 2016. A Review of Recent Developments in Natural Fibre Composites and Their Mechanical Performance. Composites Part A: Applied Science and Manufacturing. https://doi.org/10.1016/j. compositesa.2015.08.038

37. Pinto F., Boccarusso L., Fazio D.D., Cuomo S.,
Durante M., Meo M. 2020. Carbon/Hemp BioHybrid Composites: Effects of the Stacking Sequence on Flexural, Damping and Impact Properties. Composite Structures, 242, 112148. https://doi. org/10.1016/j.compstruct.2020.112148

38. Sassoni E., Manzi S., Motori A., Montecchi M., Canti M. 2014. Novel Sustainable Hemp-Based Composites for Application in the Building Industry: Physical, Thermal and Mechanical Characterization. Energy and Buildings, 77, 219-226. https:// doi.org/10.1016/j.enbuild.2014.03.033

39. Billy S., Magniont C., Lorente S. 2019. Characterization of a Precast Hemp Concrete. Part I: Physical and Thermal Properties. Journal of Building Engineering, 24, 100540. https://doi.org/10.1016/j. jobe.2018.07.016

40. Walker R., Pavia S., Mitchell R. 2014. Mechanical Properties and Durability of Hemp-Lime Concretes. Construction and Building Materials, 61, 340-348. https://doi.org/10.1016/j.conbuildmat.2014.02.065

41. Xie F., Halley P.J., Avérous L. 2012. Rheology to Understand and Optimize Processibility, Structures and Properties of Starch Polymeric Materials. Progress in Polymer Science (Oxford). https://doi. org/10.1016/j.progpolymsci.2011.07.002 